\title{
Insideout: Making Environmental Control Systems a Part of Design
}

\begin{abstract}
A - growing awareness of environmental problems and energy scarcity has led architects and engineers to re-evaluate their approaches to building design. This re-evaluation has tended to make more apparent the schism between building design and mechanical/electrical system design, as when efficient heating, ventilating, and air conditioning (HVAC) systems are designed for buildings which are inherently inefficient, or when buildings are designed as technically advanced thermos bottles that are more responsive to their support systems than to the people they support.

Tradicionally, survey courses for archirecture students in mechanical and electrical systems have tended to treat their subjects narrowly, with little stress on contexnal issues. Underlying values are not made explicit. Therefore designers
\end{abstract}

schooled in these subjects, while gaining competence in specific techniques, are unaware of the implicit values which accompany those techniques, and may be incapable of assessing their appropriateness as contexts change.

The impact of the underlying values in the use of technical systems has become powerfully apparent in the last decade as a result of the obvious degradation of the natural environment. The values which relate and govern the use of technical and natural systems and which underlie our reliance on highly technical solutions in building design are complex and deeply rooted in Western society. One of the characteristics of these values is an inherent trust in technological solutions to problems. This has been evidenced in building design by a reliance on mechanical systems to solve climate-related heat- ing and cooling problems that have themselves been created or accentuated by the building's design. Frequently, this is a result of the design being completed with litte concern for the building's energy needs, with the mechanical systems being treated as a later add-on, relying on the brute power of concentrated energy forms.

\section{Environmental Control Systems and Design}

The teaching of mechanical and electrical systems in isolation (i e, distinct from design studios), reinforces the notion that technical concerns are narrow, equipment oriented and independent. Broader environmental questions should be addressed, relating to social and political issues. To accomplish this, mechanical/

\section{EXERCISE I I}

\section{SUX PENETEATIOK AND SBADOHS}

Smakine 1s an Important part of doing th1n Feedback. and thers is no telling hou aany more gunny days there will be this season. Doa't be misled by the litheral due date: get your model together and get out in the oun with it soon!

1. Yor this part, you w111 need: Feedback building .9" call peg Angineer's scele $440 \mathrm{H}$ Sun Chart w1th "True Altitude Angle" Ind 1cator Tris tables Protractor

Mount a 9-1nch high peg on your model base. I8

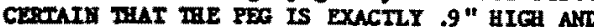
PERFECTIY VERTICAL - AND STAYS WHAT WAY!

2. The .9" vertical peg chadow plot't telle you the poesteron of the ahadou of a .9" peg for any tima of the yeur.

Kount the shud ow plot over the .9" peg on your model. Be wure that north is north and doesa't wove. By tilting the model in the sun you cen ofwinte different times of the day and year.?

4) At what times of the day on June 21 and Decemer 21 do the shedow of your building extend off your atte? Pleme draw on the site plan the winter (Dec. 21) shndows at 10 an and at 2 pm. These are prime times for absorbing solar energy for space heating. Are the shadows from your building potentinlly' b locking someone elses energy source?

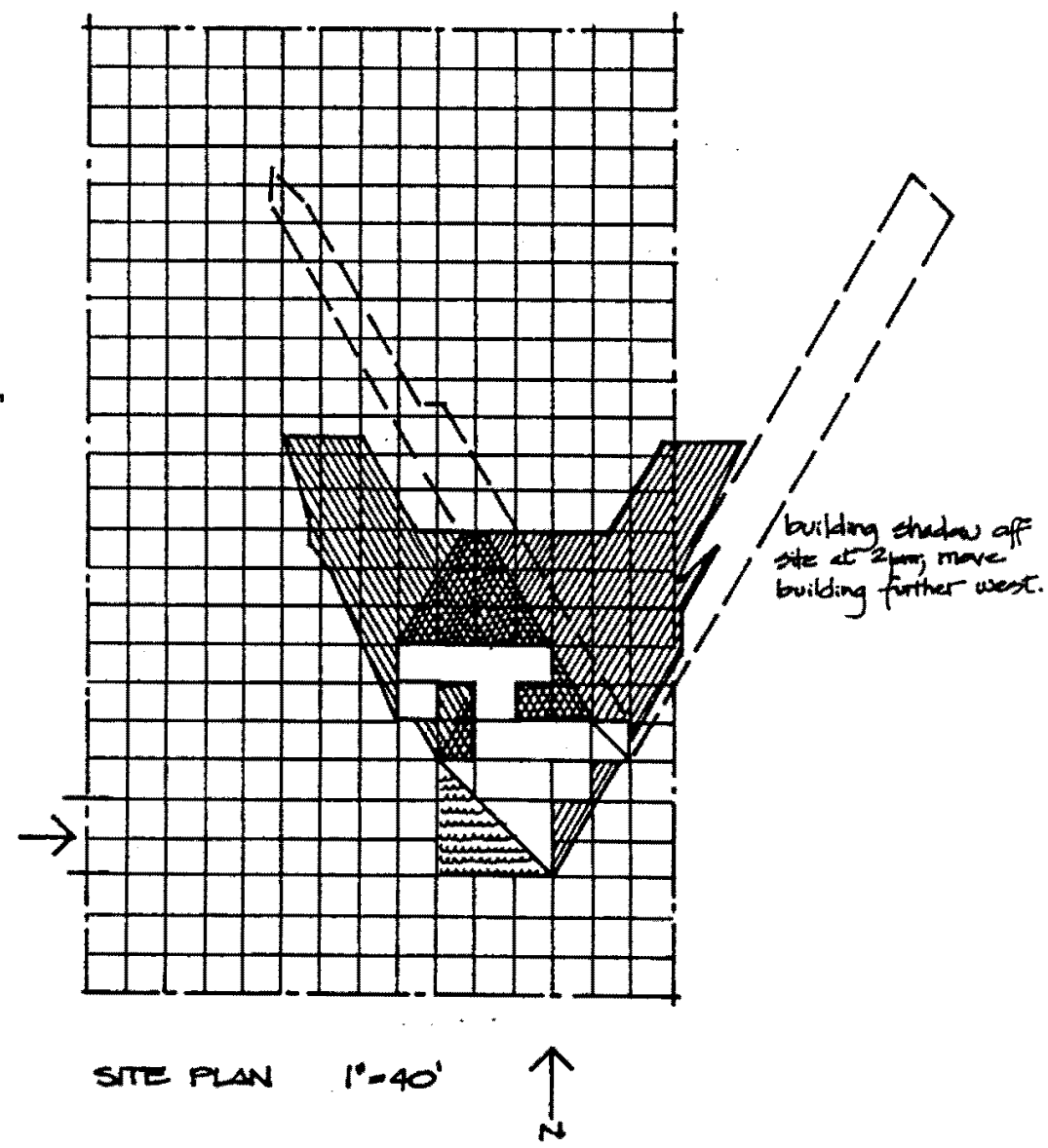

1) Excerpi from Insideout with sample solution. 
2) Excerpi from Insideout wish sample solution.

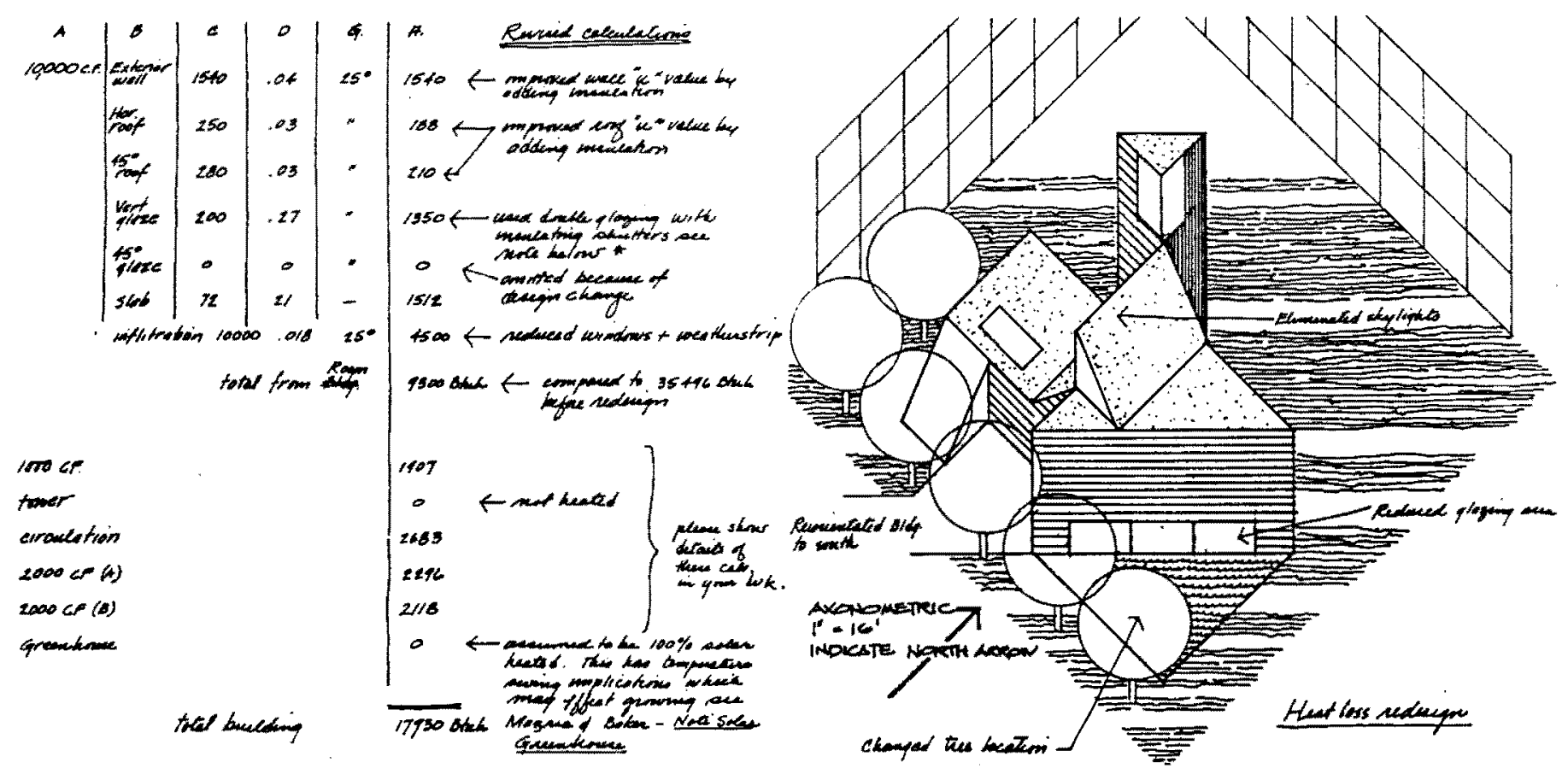

electrical system design must be integrated with a synthetic building design process so as to combine diverse programatic elements in a way that is responsive to physical, social and political context.

There seem to be three general approaches to combining environmental control systems (ECS) with design. These are: general studio courses which have a clearly identified ECS content; completely ECS-oriented project studios in which other issues are clearly subordinate; and lecture courses which are strongly related to design studio processes. The Department of Architecture at the University of Oregon uses all three approaches to some extent. My most recent interest has been in the third, in strengthening the connection between design and the introductory lecture class in ECS. This approach is important because it emphasizes how technical aspects relate to design-often difficult to illustrate in a lecture format.

The focus of this connection has been Insideout, a text/workbook that John Reynolds and I have developed. Insideout is about processes for designing buildings in terms of their thermal, luminous, sonic, water and waste environments. The intent is not to suggest that all building designs should be determined by response to these environments, but rather to point out that all design decisions, by intention or not, affect these environments, which in turn affect the natural environment. Because these decisions, which may seem secondary in the design process, can have potentially devastating impacts on the natural environment, we feel that it is important to stress their fundamental importance to design students.
Robert Venturi noted in Complexity and Contradiction in Architecture that, Architecture occurs at the meeting of interior and exterior forces of use and space. These interior and environmental forces are botb general and particular, generic and circumstantial. Architecture as the wall between the inside and outside becomes the spatial necord of this resolution and its drama.

We feel that it is critical to understand the atcitudes which lead to the distinction of inside from outside because the designer's idea of what is appropriately in and out, and what in and out are like, is primary in defining how buildings respond to their external and internal environments.

The "problem boundary" (the area in which the aspects of the problem are considered changeable) has traditionally been narrowly defined as being inside the building's skin. A constrained problem boundary is useful because there are fewer variables to consider and they are easy to evaluate. However, a narrowly defined problem boundary can lead to neglect of the larger context. For example, it is quite possible to design a sophisticated building in a hot climate with features that enhance heat gains. Therefore, no matter how efficiently the cooling system is designed, it exists in a building that is inherently inefficient. The real problem is not solved.

The educational process which we suggest is one that defines the problem boundaries broadly but simplifies the variables to the point that they can be measured, and their connection to the context readily understood. The process we use to approach the resolution of these problems follows a sequence of progressively reduced scales: off-site, site, building, and component. As an example, if our goal is to reduce energy use in a building, considerations at the various scales might be: OffSite-could the materials used to construct the building be selected on the basis of how little energy was used in their manufacture? Site-Scale-can the building be located on the site so that it takes advantage of the climate-modulating characteristics of topography and vegetation? Building Scale-can the shape and orientation of the building be changed so that it can utilize solar energy for its heating and cooling? Component Scale-can heating and cooling devices be used that make best use of natu. ral energies, and that secondarily are more highly efficient converters of fossil fuel for heating or cooling?

This scale sequence allows us to consider problems with progressively reduced problem boundaries. In addition, we also favor solutions which rely on natural energies rather than artificial ones, based on the assumption that natural solutions tend to be the least energy-intensive, and have the most porential for making a positive contriburion to the natural environment. For example, we favor utilizing solar over fossil fuel heating and natural lighting over electric lighting.

To reiterate the assumptions which gov: en this approach to building design:

1) The way in which we design buildings contributes to a serious degradation of the natural environment.

2) Because of our ultimate reliance on natural systems, in the long run environmental benefit leads to social benefit.

3) The relationship between the environment and buildings can be better understood if the problem boundaries are broadly defined.

4) If the problems are approached in a 
progressively reduced scale, it reduces the possibility that efficient small-scale solutions will develop within inefficient large scale plans.

5) Designs which utilize natural before artificial solutions are more likely to reduce environmental degradation.

\section{Organization}

Insideout is organized into four areas of concern: thermal, lighting, water/waste, and acoustics. Each section has one or more exercises. The thermal section has four exercises; sun penerration and shadows, heat loss, heat gain, and equipment and distribution. Lighting has two exercises, daylighting and electrical lighting. Daylighting precedes electric lighting in order to reinforce the notion that passive energies should be exploited before highly processed artificial energies, and that the potential of energy sources to perform work should be matched to the task. Because the daylighting exercise follows the thermal section students must resolve such conflicts as glare versus solar gain, and heat loss versus the more even illumination of north light. Electric lighting in most cases plays a backup role and tends to be task specific.

The water and waste exercise asks for the design and comparison of three systems: conventional fixtures with centralized waste treatment; low water use fixtures, solar water heating, septic tank and field, and centralized water supply; and, composting toilets, rain collection and storage, grey water filtration and irrigation, and solar water heating. The systems are compared in terms of energy and water use. The acoustic exercise frequently requires the reexamination of decisions made in previous exercises and requires tradeoffs to resolve conflicts such as the desire for hard surface mass in a direcr gain solar system versus the need for sound absorption to reduce reverberation time.

Pedagogically, we feel that it is important that exercises be presented in the consistent context of a particular building and site. Traditionally, the teaching of engineering calculations has been presented in a series of unrelated contexts, to illustrate the particular applicability of given procedures. For example, a lecture course might cover reverberation time calculated for a large auditorium, water supply sizing for an office building, and heat loss for a residence. We prefer to show interrelationships in a single building and its site, by having all calculations done on one building.

Insideout provides exercises which require the design of a building and its site, an evaluation of that design, and a redesign on the basis of that evaluation. Students are asked to design a simple, abstract building on an abstract site, so that calculations are simplified and hypotherical changes in design are easier to resolve.

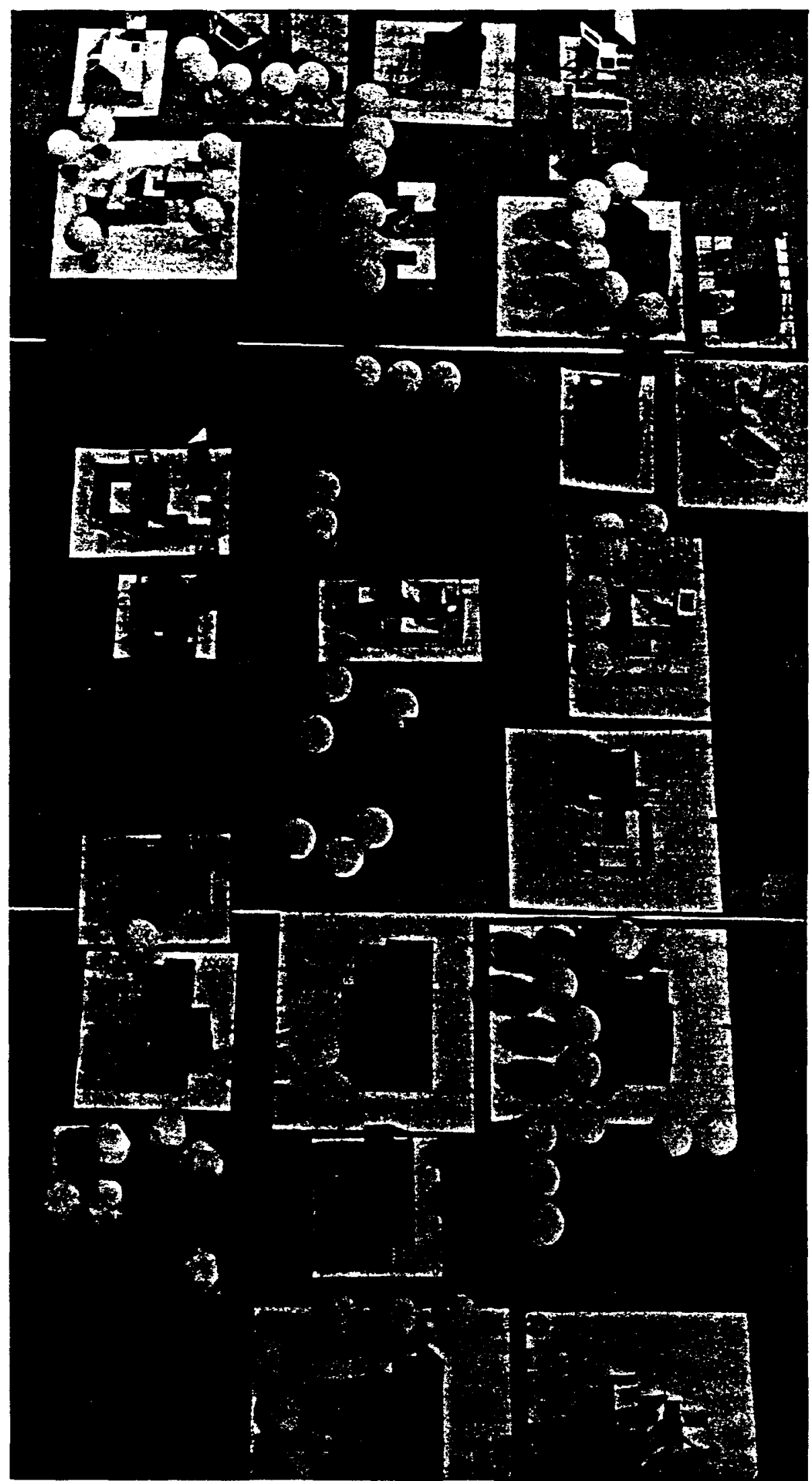

3) Student models of solutions to Insideout exercise. 
They are asked to present their initial design in an $1 / 8^{\prime \prime}=1^{\prime}-0^{\prime \prime}$ scale model and two axonometric sketches, one from the north, and one from the south. The model and sketches are updated with each redesign cycle. In the introductory section, students are also encouraged to use available ECS computer programs, written by Barbara-Jo Novitski.

While project buildings are not defined in a programmatic sense, there are a number of physical design criteria that must be met. This gives students an exposure to different building circumstances. All initial designs must have, for example, a large space of 10,000 cubic feet, two smaller spaces of 2,000 cubic feet, a tower, a circulation space, and so on. Window, skylight, and clerestory requirements are also delineated.

Each exercise in the workbook also appears in the appendix, where the authors have illustrated a sample solution to these problems. It is interesting to note that, in spite of the published examples and in spite of the uniform initial design criteria, the student designs resulting from this exercise show a remarkable degree of variation.

\section{Thermal Section}

Each major section, Thermal, Lighting, Acoustics, and $\mathrm{W} /$ ater/Waste is organized in a similar manner. Each has an introduction and a series of exercises. The following quote is from the introduction to the section on the thermal environment.

We bave devoted a large proportion of the exercises to thermal considerations because of their potentially high impact on building design and amounts of energy used in beating and cooling buildings.

It is useful to make an analogy between the response of animals to their thermal environment and the response of buildings to theirs. There are three basic ways in which organisms respond to their thermal environment; migration, form, and metabolism. In migration, they move from an environment that is too cold or too bot to one that is comfortable. This may bappen seasonally as with birds, or diurnally, as with lizards. As for form, animals have large or small skin areas in relation to their volume ta increase or decrease their rate of beat loss to the environment. For example, the form of an elephant's large ear surface area belps to dissipate the interior beat generated in the large volume. Metabolism refers to animals' iniemal cbemical conversion processes. These work processes require food energy and result in the production of beat. Consequently, those animals witb a high beat loss cat large amounts of foad, which is converted to beat within their bodies to balance their beat loss.

These three forms of thermal response bave their analogies in buildings. Migration or moving from one area to anotber bas numerous examples, especially in low sechnology indige-
4) Student modals of solutions to Insideour exercise.

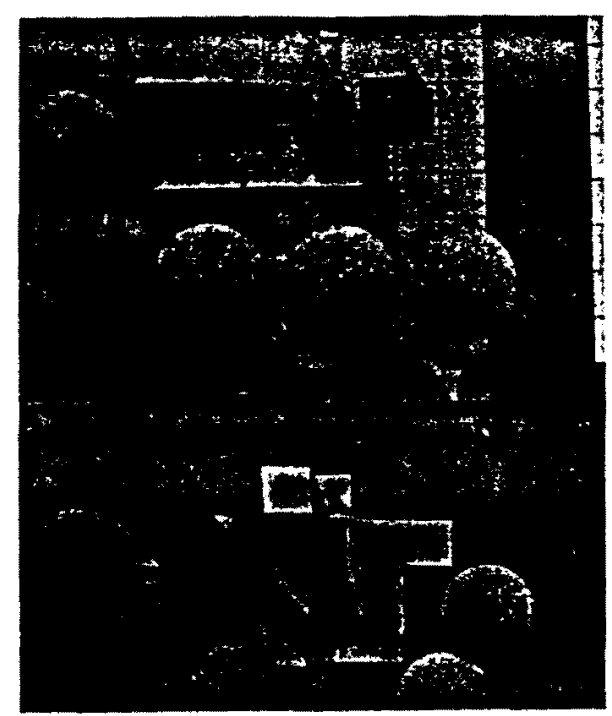

nous arcbitecture. An example in residential buildings is the use of the sleeping porch on bot summer nights. As a design factor, form implies size, skin area, orientation, volume, openings, articulation, etc. Metabolism involves the fuel sustained processes of the building.

Current design practice usually separates form and metabolism in order to simplify preliminary design development and does not recombine them until later in the process when building form must be used as the basis for determining the metabolic rate. However, even though form and metabolism are dependent upon different sets of variables, they are inirinsically linked: while form is a function of aesthetic attitudes, land values, material availability, use patterns, circulation routes, etc, metabolic rate is a function of how well the form uses available energies to modify climate.

The text is extensively foornoted. We do not attempt to treat each subject comprehensively but concentrate on providing a set of procedures or a process which connects these subjects. However, we do encourage student use of outside references, and maintain an updated bibliography.

The first exercise in Insideout involves a study of sun patterns and shadow plots. By tilting their models in different ways toward the sun, students can answer a number of different questions: What are the best times for solar heating, for inside or outside spaces? Does your building infringe on others' sun rights? How does the orientation of outside spaces affect their potential usefulness throughout the year? After answering these questions, the students are asked to rearrange the building and vegetation on the site to improve the design in light of their responses.

In the heat-loss section, students are asked to reconsider building materials, skin area, design temperatures, solar exposure, vegetation, etc. Each design is syste- matically evaluated in terms of its responsiveness to each scale: Are vegetation, wall composition and building orientation combined to form the most efficient thermal environment? Techniques for decreasing heat loss are then suggested at each scale, and again the students are asked to submit a revised design, one which will meet criteria of a $12.5 \mathrm{Btuh} / \mathrm{sf}$ heat loss under average January conditions in Eugene.

The third secrion involves heat gain, in both the summer and winter modes. Minimizing summer gain and maximizing winter gain is a difficult architectural problem, one that is frequently avoided by researchers as well as practitioners. In this exercise, the students are required to look at both simultaneously. They are encouraged to provide creative solutions involving educated judgments based on their understanding of the tradeoffs. They are asked to consider space usage patterns, window configuration and orientation, surface/ volume ratios, potentials for natural ventilation versus infiltration problems, etc. After they have tried to balance tradeoffs, they are asked to check their building against the standards of ASHRAE 90-75.

In the final exercise of the thermal section, the students are asked to do a conventional mechanical equipment sizing calculation and distribution system layout, based on the heating or cooling requirements that remain after their three redesigns.

\section{Conclusion}

The result of this approach to teaching ECS is that students are exposed to a full range of design solutions at all scales and at several technological levels. This not only gives them experience with possible solutions which are integral with the building design but it provides them an insight about the breadth of possibilities. Therefore, they are betrer equipped to evaluate the social values inherent in each of those possible solutions.

The fate of our culture may be profoundly dependent on technologists. As architectural educators, we should insist that future designers be taught about the impact that their work may have and the importance of their integrating a sense of environmental responsibility with a set of social values larger than their own. 